\title{
Microstructural Evolution of a Continuously Cooled Air Hardening Steel
}

\author{
K. Brunelli $\cdot$ P. Bassani $\cdot$ N. Lecis $\cdot$ L. Peruzzo $\cdot$ \\ C. Maranzana $\cdot$ M. Dabalà
}

Received: 20 September 2012/Revised: 18 January 2013/Accepted: 24 January 2013/Published online: 15 February 2013

(C) Springer Science+Business Media New York and ASM International 2013

\begin{abstract}
This study studied the phase transformations occurring at different continuous cooling rates in an air hardening steel used in the rock-crushing industry. Samples of this steel were submitted for calorimetric testing using the differential scanning calorimetry (DSC) technique. In the experimental run, the samples were heated at the rate of $0.33{ }^{\circ} \mathrm{C} / \mathrm{s}$ from 50 to $1050{ }^{\circ} \mathrm{C}$ and equilibrated at this temperature for $900 \mathrm{~s}$, then cooled at seven different cooling rates between 0.05 and $0.5^{\circ} \mathrm{C} / \mathrm{s}$. For all the cooling rates, the DSC traces of the samples showed a first exothermic peak at about $500{ }^{\circ} \mathrm{C}$ and for samples cooled at rates higher than $0.15{ }^{\circ} \mathrm{C} / \mathrm{s}$, a second exothermic peak at about $295{ }^{\circ} \mathrm{C}$ was observed. From the microstructural investigations carried out by light microscopy (LM) and scanning electron microscopy (SEM), it was observed that all the samples after DSC treatment were characterized by the presence of bainite. In the samples cooled at rates higher than $0.15^{\circ} \mathrm{C} / \mathrm{s}$, martensite was also detected. Comparing the results of DSC and SEM, it was concluded that the first peak at $500{ }^{\circ} \mathrm{C}$ corresponds to the
\end{abstract}

\author{
K. Brunelli $(\bowtie) \cdot$ M. Dabalà \\ DII, University of Padua, Via Marzolo 9, 35131 Padua, Italy \\ e-mail: katya.brunelli@unipd.it \\ P. Bassani \\ CNR-IENI, Lecco, Italy \\ N. Lecis \\ Department of Mechanics, Polytechnic Institute of Milan, Milan, \\ Italy \\ L. Peruzzo \\ CNR-IGG, Via Gradenigo 6, 35131 Padua, Italy \\ C. Maranzana \\ Fonderia e Acciaierie Roiale FAR, Udine, Italy
}

austenite $\rightarrow$ bainite transformation, while the second peak at $295^{\circ} \mathrm{C}$ corresponds to the austenite $\rightarrow$ martensite transformation. The experimentally determined bainite and martensite start temperatures were compared to the values derived from a number of well-known empirical equations.

Keywords Differential scanning calorimetry · Martensite · Bainite $\cdot$ Continuous cooling $\cdot$ Segregation $\cdot$ Carbon alloy steel $\cdot$ Electron microscopy $\cdot$ Metallography

\section{Introduction}

The rock-crushing industry, in particular, the recycling industry, is looking toward new materials, other than high manganese steel, to build impact crushers, since for these applications the operating conditions are not severe enough to work-harden the manganese steel. Attention is being focused on a low-alloy steel containing $\mathrm{Cr}, \mathrm{Ni}, \mathrm{Mn}$, and Mo, which belongs to the family of air hardening steels and exhibits a good combination of wear resistance and toughness [1]. Despite the technological importance of these materials, only a few studies have been carried out to characterize the phase transformations occurring during cooling.

Transformation kinetics of low-alloy steels are rather complex. The austenite-to-bainite and martensite transformations depend on (i) the chemical composition of the steel; (ii) the austenite grain size preceding transformation, and (iii) the cooling rate. The methods most commonly used for determining structural transformations of lowalloy steels in terms of thermal cycling are dilatometry and thermal analysis [2-4]. Dilatometry provides information on the consequences of transformations by studying changes in the sample length resulting from phase changes. 
Table 1 Composition of steel alloy used in this study

\begin{tabular}{lllllllllllll}
\hline Element & $\mathrm{C}$ & $\mathrm{Cr}$ & $\mathrm{Ni}$ & $\mathrm{V}$ & $\mathrm{Mo}$ & $\mathrm{Mn}$ & $\mathrm{Si}$ & $\mathrm{P}$ & $\mathrm{S}$ & $\mathrm{Al}$ & $\mathrm{Fe}$ \\
\hline $\mathrm{wt} \%$ & 0.45 & 3 & 1 & 0.01 & 0.5 & 0.7 & 0.5 & 0.005 & 0.015 & 0.015 & $\mathrm{Bal}$. \\
\hline
\end{tabular}

Table 2 Sample Cooling Rates

\begin{tabular}{llllllll}
\hline Sample & S1 & S2 & S3 & S4 & S5 & S6 & S7 \\
\hline Cooling rate $\left({ }^{\circ} \mathrm{C} / \mathrm{s}\right)$ & 0.05 & 0.075 & 0.1 & 0.15 & 0.2 & 0.3 & 0.5 \\
\hline
\end{tabular}

When steel undergoes a phase change, the lattice structure becomes altered and produces a change in specific volume. Thermal analysis, in particular, differential scanning calorimetry (DSC), is a technique well suited for studying phase-transformation kinetics that involve some kind of heat effect: the transformations in $\mathrm{Fe}-\mathrm{C}$ and low-alloy steels upon heating and cooling involve both heat of transformation and changes in heat capacity. DSC is a technique in which the difference in heat flow between the sample and a reference material is monitored as a function of time or temperature. The theoretical background of this technique and the usual method of analysis are described in several textbooks $[5,6]$.

In industrial heat-treating operations, steel is not isothermally transformed, but is continuously cooled from the austenite temperature to room temperature. Therefore, continuous cooling transformation (CCT) diagrams of steel play an important role in the development of new products. They may be used to predict the microstructures and properties of steel, and can be helpful in the design of new steel alloys.

The aim of this study is to study the effects of different continuous cooling rates, obtained by the DSC technique, on the microstructural transformations in a low-alloy steel containing $\mathrm{Cr}, \mathrm{Ni}, \mathrm{Mn}$, and $\mathrm{Mo}$.

\section{Experimental}

The composition of the steel used in the present study is listed in Table 1. The material, in the as-cast condition, was supplied by the steel company Fonderie Acciaierie Roiale. Specimens for DSC analysis were cut using a metallographic diamond cutting saw and then ground to the final shape (a cylinder with diameter of $2.5 \mathrm{~mm}$, height of $2 \mathrm{~mm}$ ) with emery papers. Final mass of each sample was approximately $100 \mathrm{mg}$. The heating chamber was fluxed with argon. In the experimental run, the samples were heated at the rate of $0.33{ }^{\circ} \mathrm{C} / \mathrm{s}$ from 50 to $1050{ }^{\circ} \mathrm{C}$ and equilibrated at this temperature for $900 \mathrm{~s}$, and then cooled at rates between 0.05 and $0.5{ }^{\circ} \mathrm{C} / \mathrm{s}$, as summarized in

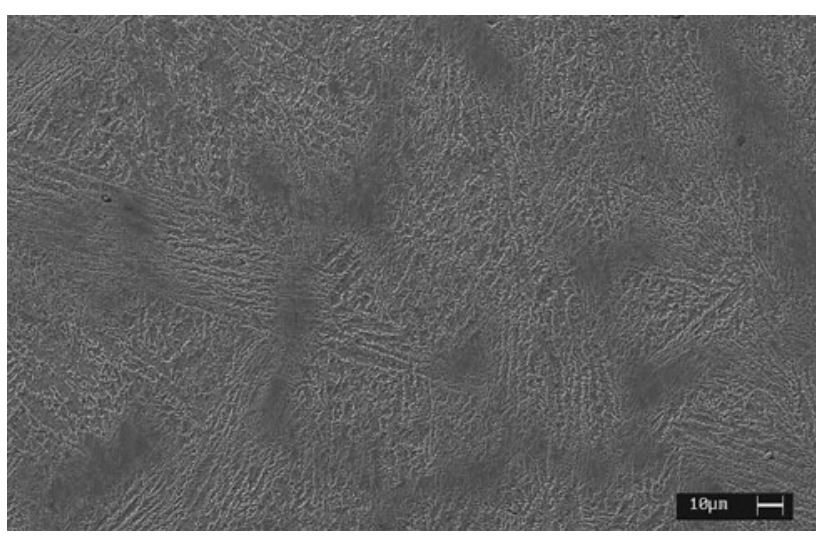

Fig. 1 Microstructure of the as-cast material (SEM-SE image)

Table 2. After DSC treatment, the samples were mounted in epoxy resin and polished by metallographic procedures. The microstructure of the samples, after etching with nital, were characterized using a light microscope (LM) and a scanning electron microscope (SEM) equipped with an energy dispersive $\mathrm{x}$-ray spectroscopy (EDS) system. Accelerating voltages of 15 and $25 \mathrm{kV}$ were used in secondary electron (SE) mode and in backscattered electron mode, respectively. Electron backscattered diffraction (EBSD) was performed at $30 \mathrm{kV}$ on selected samples. Hardness measurements were performed with a Vickers indenter and an applied load of $200 \mathrm{~g}$. The amount of bainite in the final microstructure was determined using image analysis. An etching solution, consisting of $14 \mathrm{~mL} / \mathrm{L}$ of $\mathrm{HF}, 6 \mathrm{~mL} / \mathrm{L} \mathrm{HNO}_{3}$, and $40 \mathrm{~mL} / \mathrm{L}$ of $\mathrm{H}_{2} \mathrm{O}$, was employed to reveal bainite in the steel as the darkest microstructural constituent. To obtain statistically reliable results, 15 images taken from the same sample were analyzed.

\section{Results and Discussion}

Figure 1 shows the SEM-SE image of the material in the as-received microstructural condition, obtained during cooling in air after casting; the microstructure of the as-cast material consisted mainly of bainite (ferrite and iron carbides) and retained austenite.

In Fig. 2, the DSC thermogram, obtained during heating, is shown. In this experimental run, the samples were heated at the rate of $0.33{ }^{\circ} \mathrm{C} / \mathrm{s}$ from 50 to $1050{ }^{\circ} \mathrm{C}$. Analysis of the DSC thermogram provides a means to distinguish the presence of two distinct endothermic peaks. 
If the starting microstructure of the steel is principally bainite, then the changes in the main phase, resulting from continuous heating, may be placed in the following order with respect to increasing temperature: (i) the magnetic transition from a ferromagnetic state to a paramagnetic state, and (ii) the ferrite + carbide $\rightarrow$ austenite transformation.

After these considerations, the first peak starting at $700{ }^{\circ} \mathrm{C}$ can be attributed to the magnetic transformation point [7], where $T_{\mathrm{C}}\left(760{ }^{\circ} \mathrm{C}\right)$ corresponds to the Curie point, e.g., the temperature at which the metal loses its ferromagnetic properties (for pure iron the Curie point is at $770{ }^{\circ} \mathrm{C}$ ).

The second endothermic peak, overlapping partially the first one, and enclosed between $780{ }^{\circ} \mathrm{C}\left(A_{\mathrm{C} 1}\right.$ austenite onset temperature $)$ and $850{ }^{\circ} \mathrm{C}\left(A_{\mathrm{C} 3}\right.$ : austenite finish temperature) characterizes the ferrite + carbide + austenite phase region [7]. After $A_{\mathrm{C} 3}$, the sample is mostly austenitic, although the complete homogenization of this phase may not yet be realized at this stage, as attested by the presence of an endothermic peak at about $930{ }^{\circ} \mathrm{C}$ [8]. Indeed, this last peak can be correlated to the progressive dissolution of carbides in austenite.

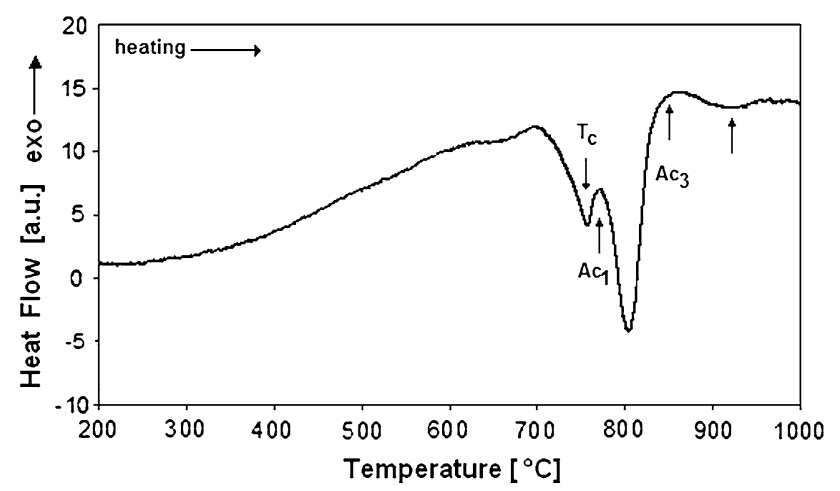

Fig. 2 DSC trace obtained during sample heating
The DSC traces of the samples obtained under different cooling rates are shown in Fig. 3. As can be clearly seen, all scans show a wide exothermic peak ranging from about 495-275 ${ }^{\circ} \mathrm{C}$. Another, smaller exothermic peak, evident only for the samples cooled at rates higher than $0.1{ }^{\circ} \mathrm{C} / \mathrm{s}$, can be observed at about $265^{\circ} \mathrm{C}$. For this second peak, a start temperature of about $290{ }^{\circ} \mathrm{C}$ can be assumed; a more precise definition of the starting temperature is difficult, because of the possible overlapping of the last part of the previous peak with the beginning of the one subsequently following. In addition, the end temperature of the peak cannot be determined.

CCT diagrams are very useful in representing the transformation characteristics of steel, not isothermally heat treated, and in revealing the role of alloying elements in influencing the microstructure of the steel. Regarding the decomposition of austenite, the CCT diagrams can be divided into at least two curves: one represents the reconstructive transformation (ferrite and pearlite), and the other displacive reactions (bainite and martensite). Considering the composition of this steel and the kinetics of the phase transformations of air hardening steels, it is plausible to expect that the reconstructive transformations of austenite are delayed, with the CCT curve of this transformation shifted to longer times.

Based on these considerations, it can be assumed that the first peak corresponds to the austenite $\rightarrow$ bainite transformation, and the second peak to the austenite $\rightarrow$ martensite transformation. Therefore, the temperature of $500{ }^{\circ} \mathrm{C}$ is attributable to the bainite start temperature $\left(B_{\mathrm{S}}\right)$, and the temperature of $290{ }^{\circ} \mathrm{C}$ to the martensite start temperature $\left(M_{\mathrm{S}}\right)$.

Bainite forms by the decomposition of austenite at a temperature which is above $M_{\mathrm{S}}$, but below the one at which fine pearlite forms. The bainite start temperature $B_{\mathrm{S}}$ is defined as the highest temperature at which ferrite can
Fig. 3 DSC traces obtained during sample cooling

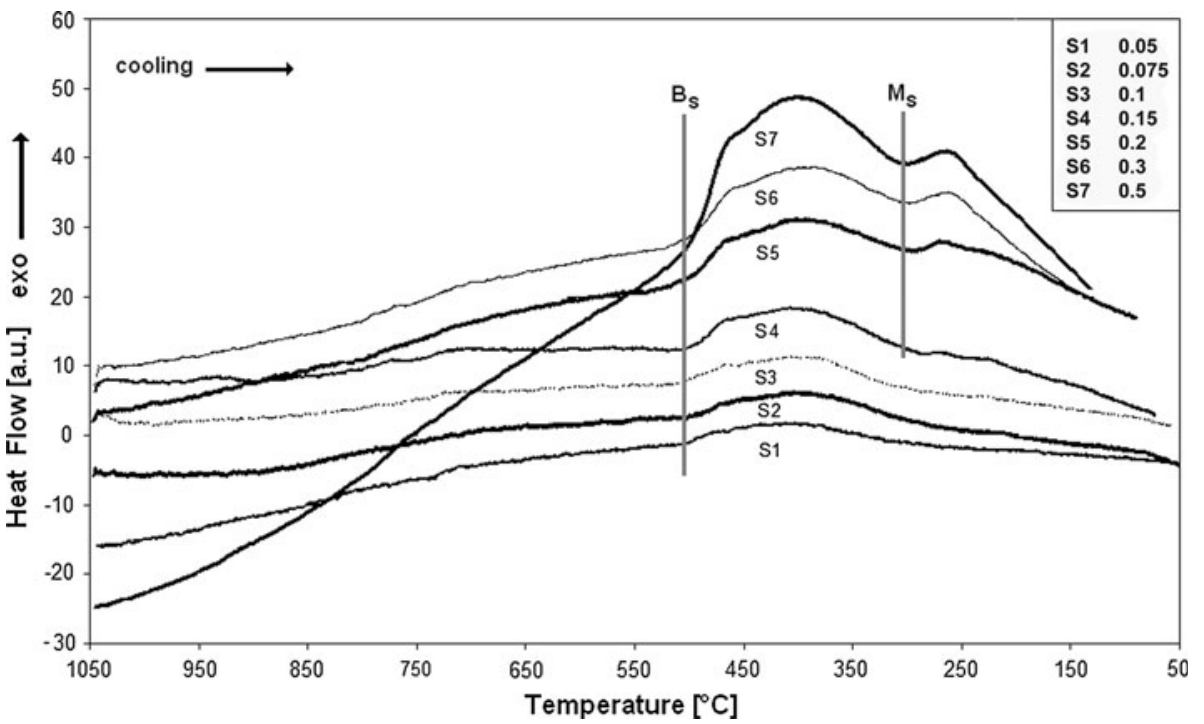


transform by displacive transformation. From this investigation, it is concluded that the upper temperature, at which bainite transformation can start, appears almost insensitive to the cooling rate. Similar results were found by Bodnar et al. [9]. This phenomenon is in fact expected when no other transformation precedes bainite [10]. As a matter of fact, $B_{\mathrm{S}}$ should not be affected by cooling rate, since it is generally accepted that the ferrite component of bainite inherits the carbon content of the parent austenite, no matter how slow the cooling rate will be $[11,12]$. Therefore, regardless of whether it is an isothermal transformation diagram or a CCT diagram, the $B_{\mathrm{S}}$ temperature should be the same.

A common observation is that $B_{\mathrm{S}}$ temperature is very sensitive to the chemical composition of the steel, indicating that the influence of solutes is more than just thermodynamic, and considerable study has been devoted to developing quantitative models for its compositional dependency. The experimentally-derived $B_{\mathrm{S}}$ temperature for this steel was compared with the values derived from the empirical equations reported by others [9, 13-15].

The most popular empirical equation expressing the $B_{\mathrm{S}}$ temperature as a function of steel chemistry is that of Steven and Haynes [13]:

$$
B_{\mathrm{S}}\left({ }^{\circ} \mathrm{C}\right)=830-270 \mathrm{C}-90 \mathrm{Mn}-37 \mathrm{Ni}-70 \mathrm{Cr}-83 \mathrm{Mo}
$$$$
\text { (in wt \%) }
$$

Bodnar et al. [9] determined the CCT diagrams for a series of $\mathrm{Fe}-\mathrm{Ni}-\mathrm{Cr}-\mathrm{Mo}-\mathrm{C}$ steels and they derived the following equation:

Table 3 Bainite start temperatures obtained using various equations from the literature

\begin{tabular}{lllllll}
\hline & $\begin{array}{l}\text { Experimentally } \\
\text { derived }\end{array}$ & $\begin{array}{l}\text { Steven and Haynes } \\
{[13]}\end{array}$ & $\begin{array}{l}\text { Bodnar et al. } \\
{[9]}\end{array}$ & $\begin{array}{l}\text { Kirkaldy and Venugopalan } \\
{[14]}\end{array}$ & $\begin{array}{l}\text { Zhao et al. } \\
{[15]}\end{array}$ & $\begin{array}{l}\text { Kunitake and Okada } \\
{[17]}\end{array}$ \\
\hline$B_{\mathrm{S}}\left({ }^{\circ} \mathrm{C}\right)$ & 500 & 357 & 281 & 430 & 458 & 492 \\
\hline
\end{tabular}
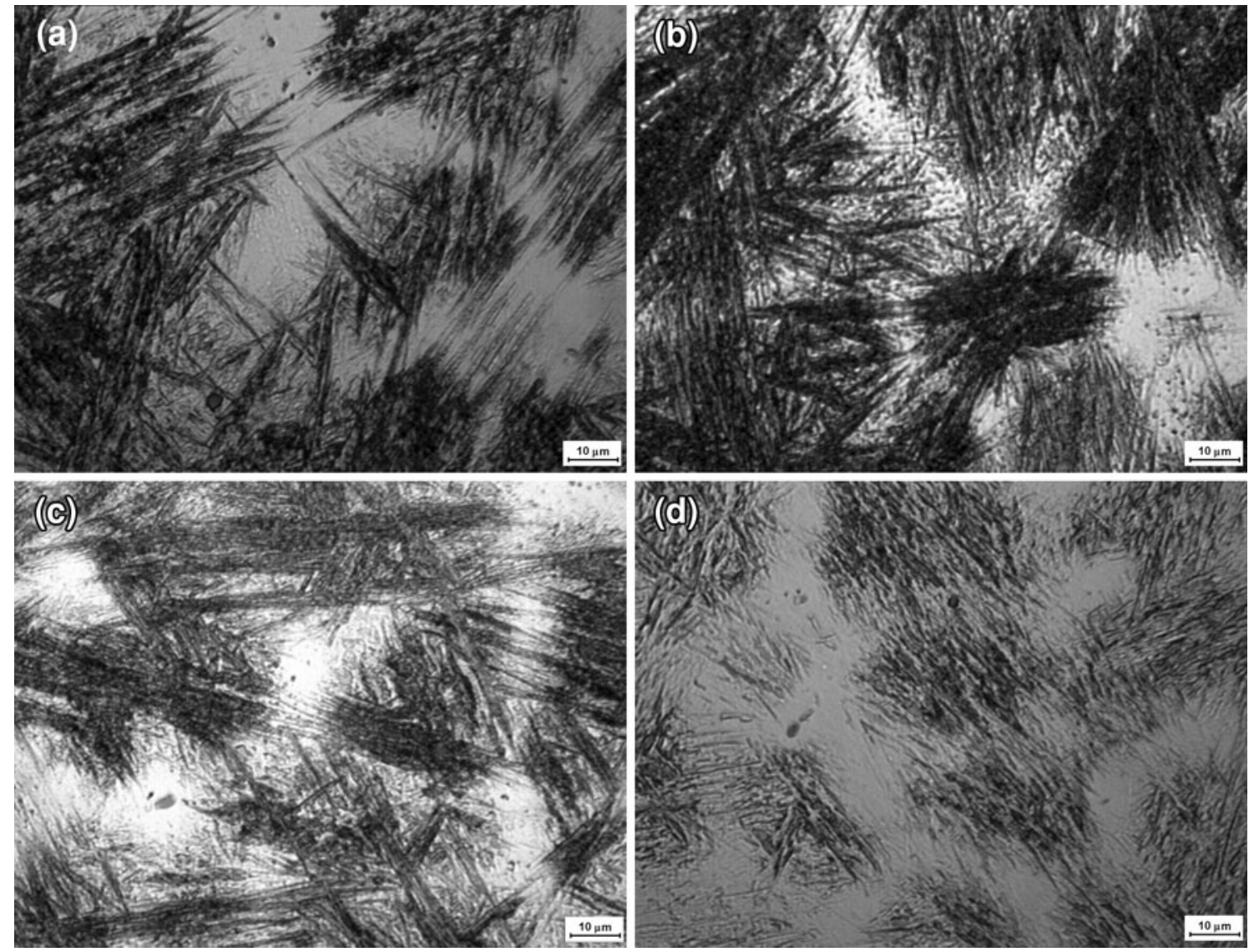

Fig. 4 LM image of a sample S2 $\left(0.075{ }^{\circ} \mathrm{C} / \mathrm{s}\right)$; b sample S3 $\left(0.1{ }^{\circ} \mathrm{C} / \mathrm{s}\right)$; c sample S4 $\left(0.15^{\circ} \mathrm{C} / \mathrm{s}\right)$; and d sample S6 $\left(0.3{ }^{\circ} \mathrm{C} / \mathrm{s}\right)($ etched with nital) 

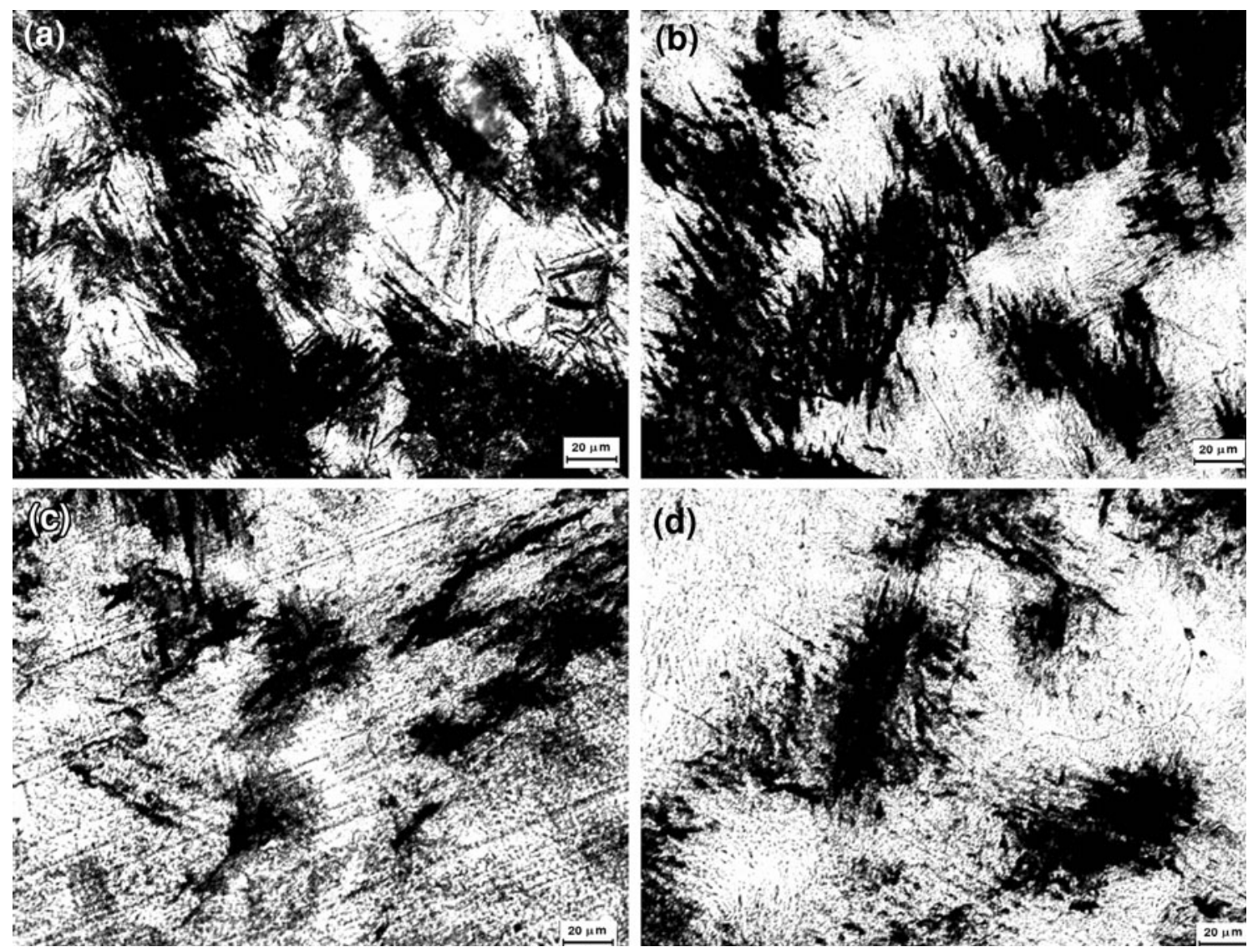

Fig. 5 LM image of a sample $\mathrm{S} 2\left(0.075{ }^{\circ} \mathrm{C} / \mathrm{s}\right)$; b sample $\mathrm{S} 4\left(0.15{ }^{\circ} \mathrm{C} / \mathrm{s}\right)$; c sample S6 $\left(0.3{ }^{\circ} \mathrm{C} / \mathrm{s}\right)$; and d sample $\mathrm{S} 7\left(0.5{ }^{\circ} \mathrm{C} / \mathrm{s}\right)($ etched with $14 \mathrm{~mL} /$ $\mathrm{L}$ of $\mathrm{HF}, 6 \mathrm{~mL} / \mathrm{L} \mathrm{HNO}_{3}, 40 \mathrm{~mL} / \mathrm{L}$ of $\mathrm{H}_{2}$ )

$B_{\mathrm{S}}\left({ }^{\circ} \mathrm{C}\right)=844-597 \mathrm{C}-63 \mathrm{Mn}-16 \mathrm{Ni}-78 \mathrm{Cr} \quad($ in wt $\%)$

However, for the steel analyzed in this study, the values derived from these equations are considerably lower than the experimental value of $B_{\mathrm{S}}$ obtained from DSC analysis (Table 3).

Kirkaldy and Venugopalan [14] modified Steven and Haynes' equation formula using US steel isothermal transformation diagrams to predict the $B_{\mathrm{S}}$ temperatures of low-alloy steel, as well as high alloy steels. Their equation is:

$$
\begin{aligned}
B_{\mathrm{S}}\left({ }^{\circ} \mathrm{C}\right)= & 656-35 \mathrm{Mn}-75 \mathrm{Si}-34 \mathrm{Cr}-41.2 \mathrm{Mo}-15.3 \mathrm{Ni} \\
& -57.5 \mathrm{C} \quad(\text { in wt } \%)
\end{aligned}
$$

The value for the current steels obtained with this equation approached the experimental $B_{\mathrm{S}}$ temperature obtained in this study. Similarly, reasonable agreement was found when using the equation obtained recently by Zhao et al. [15]:

$B_{\mathrm{S}}\left({ }^{\circ} \mathrm{C}\right)=630-45 \mathrm{Mn}-40 \mathrm{~V}-35 \mathrm{Si}-30 \mathrm{Cr}-25 \mathrm{Mo}-20 \mathrm{Ni}$

(in wt $\%$ )
Table 4 Bainite amount as obtained through image analysis

\begin{tabular}{llllllll}
\hline Sample & S1 & S2 & S3 & S4 & S5 & S6 & S7 \\
\hline Bainite \% & 55 & 58 & 60 & 52 & 49 & 27 & 26
\end{tabular}

However, these two values are still 70 and $50{ }^{\circ} \mathrm{C}$, respectively, lower than the experimental data.

The difference between the calculated and experimental values of $B_{\mathrm{S}}$ could be attributed to the composition of the steel in this study, which is slightly different from those analyzed in literature; this steel is characterized by higher concentrations of $\mathrm{Cr}, \mathrm{Ni}, \mathrm{Mn}$, and $\mathrm{Mo}$, and the interactions among these alloying elements can limit applicability of empirical equations derived from less alloyed steel data.

Indeed, Zhao et al. also evidenced that for the steels with the highest amount of alloying elements, a marked difference was observed between the $B_{\mathrm{S}}$ values calculated with the empirical equations and the $B_{\mathrm{S}}$ experimental values. Moreover, comparing the $B_{\mathrm{S}}$ experimental value of this study to the experimental $B_{\mathrm{S}}$ value of steels with a similar composition [16], it was found that the values are similar and all near to $500{ }^{\circ} \mathrm{C}$. This supports the hypothesis that 
the steel of this study is out of the validity range of the empirical equations above reported.

Alternatively, acceptable agreement is obtained with the application of Kunitake and Okada's equation [17]:

$$
\begin{aligned}
B_{\mathrm{S}}\left({ }^{\circ} \mathrm{C}\right)= & 732-85 \mathrm{Mn}+216 \mathrm{Si}-47 \mathrm{Cr}-39 \mathrm{Mo}-37 \mathrm{Ni} \\
& -202 \mathrm{C} \quad(\text { in wt } \%)
\end{aligned}
$$

The empirical equation in Kunitake and Okada was arrived at by analyzing data for steels in a wide range of composition, including the steel composition investigated in this study.

The experimental value and all values obtained with the empirical equation are shown in Table 3.
It was observed that the $M_{\mathrm{S}}$ temperature determined by DSC analysis exhibits a difference of only $25{ }^{\circ} \mathrm{C}$ with the value of $270{ }^{\circ} \mathrm{C}$ estimated using Andrews' empirical formula (6) [18]:

$$
\begin{aligned}
M_{\mathrm{S}}\left({ }^{\circ} \mathrm{C}\right)= & 539-423 \mathrm{C}-30.4 \mathrm{Mn}-17.7 \mathrm{Ni}-12.1 \mathrm{Cr}-7.5 \mathrm{Mo} \\
& (\text { in wt } \%)
\end{aligned}
$$

LM was used to provide an overview of the microstructures that resulted from the DSC different cooling rates. The LM analysis of the samples obtained at lower cooling rates showed a fine-scale microstructure with acicular morphology that it made it impossible to distinguish if the microstructure was related to bainite or martensite phase,
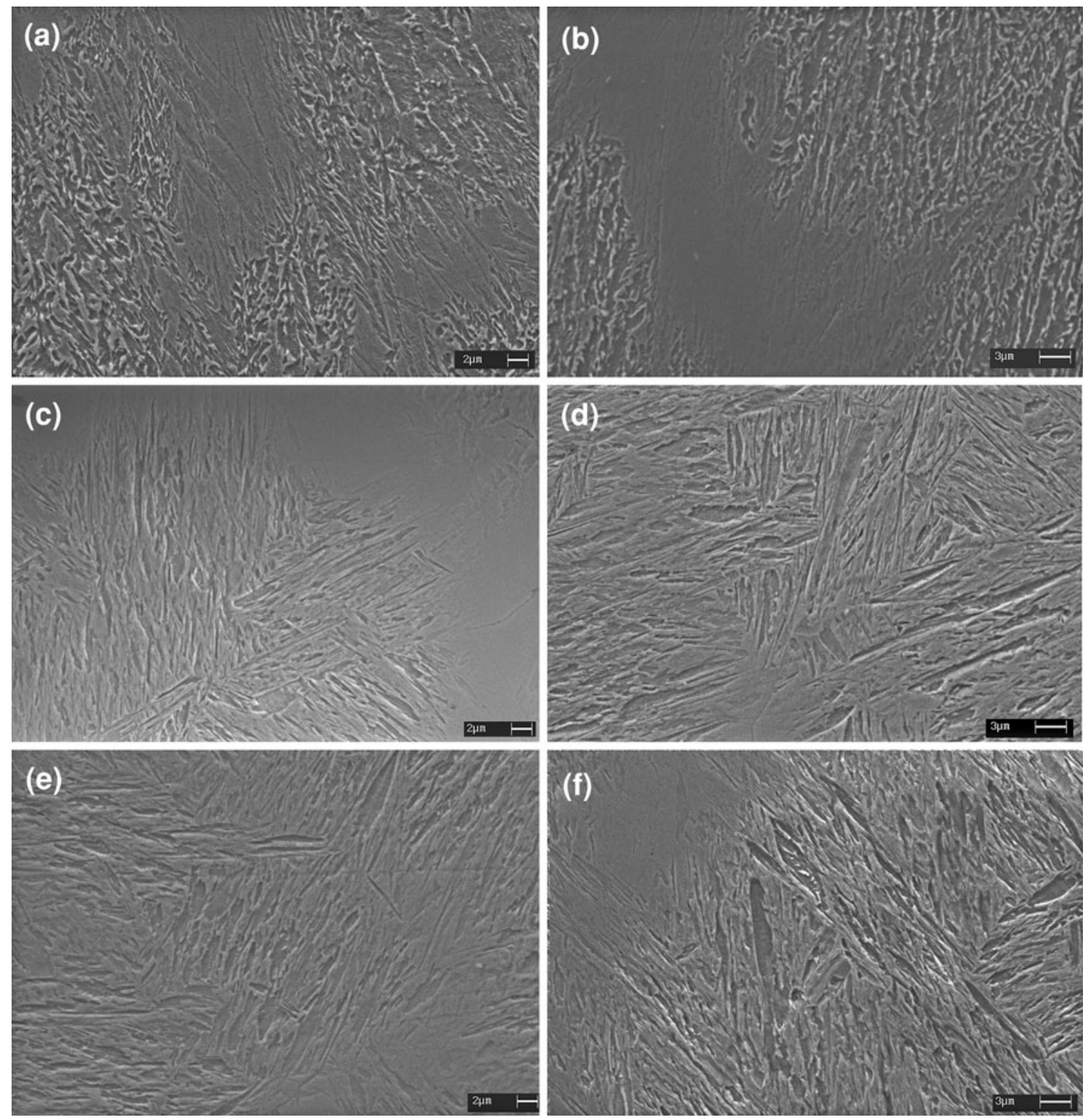

Fig. 6 SEM-SE image of a sample $\mathrm{S} 1\left(0.05{ }^{\circ} \mathrm{C} / \mathrm{s}\right)$; b sample $\mathrm{S} 3\left(0.1{ }^{\circ} \mathrm{C} / \mathrm{s}\right)$; c sample $\mathrm{S} 4\left(0.15{ }^{\circ} \mathrm{C} / \mathrm{s}\right)$; d sample S5 $\left(0.2{ }^{\circ} \mathrm{C} / \mathrm{s}\right)$; e sample S6 $\left(0.3^{\circ} \mathrm{C} / \mathrm{s}\right)$; and $\mathbf{f}$ sample $\mathrm{S} 7\left(0.5^{\circ} \mathrm{C} / \mathrm{s}\right)$ (etched with nital) 
Fig. 7 High magnification SEM-SE image of a sample S1 and $\mathbf{b}$ sample S6 (etched with nital)
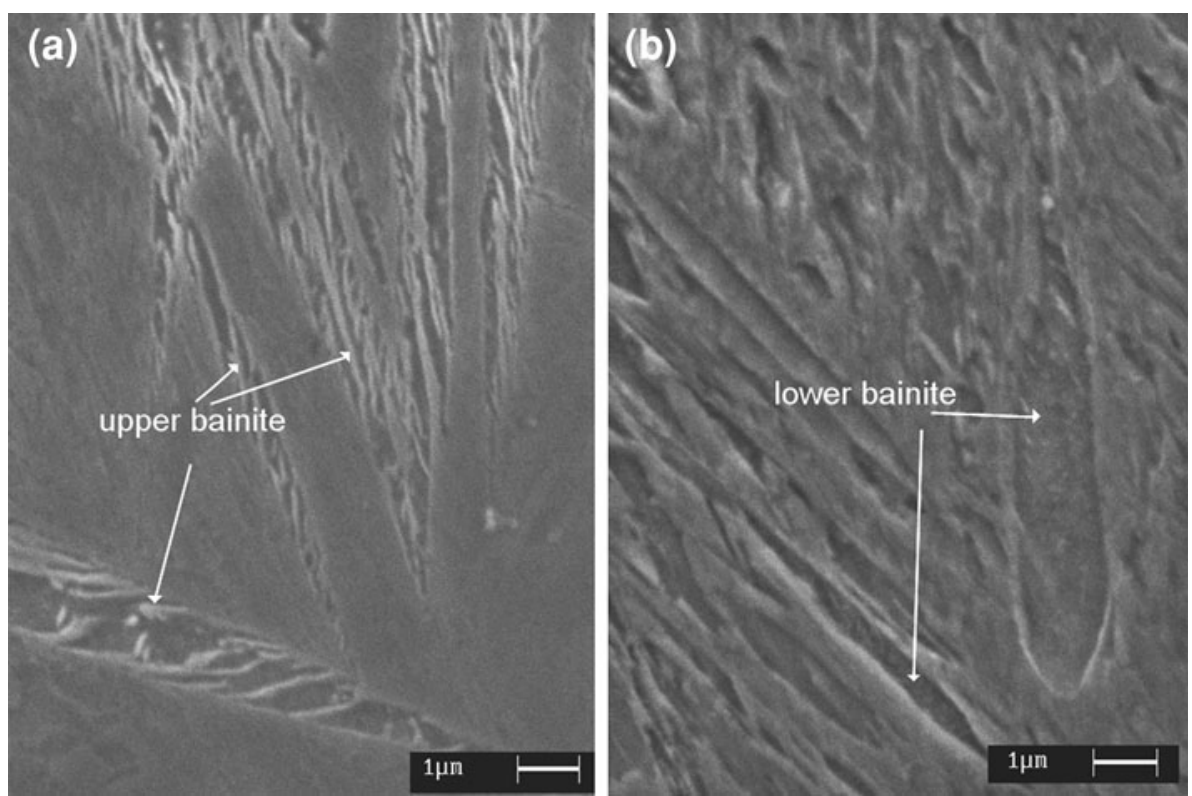
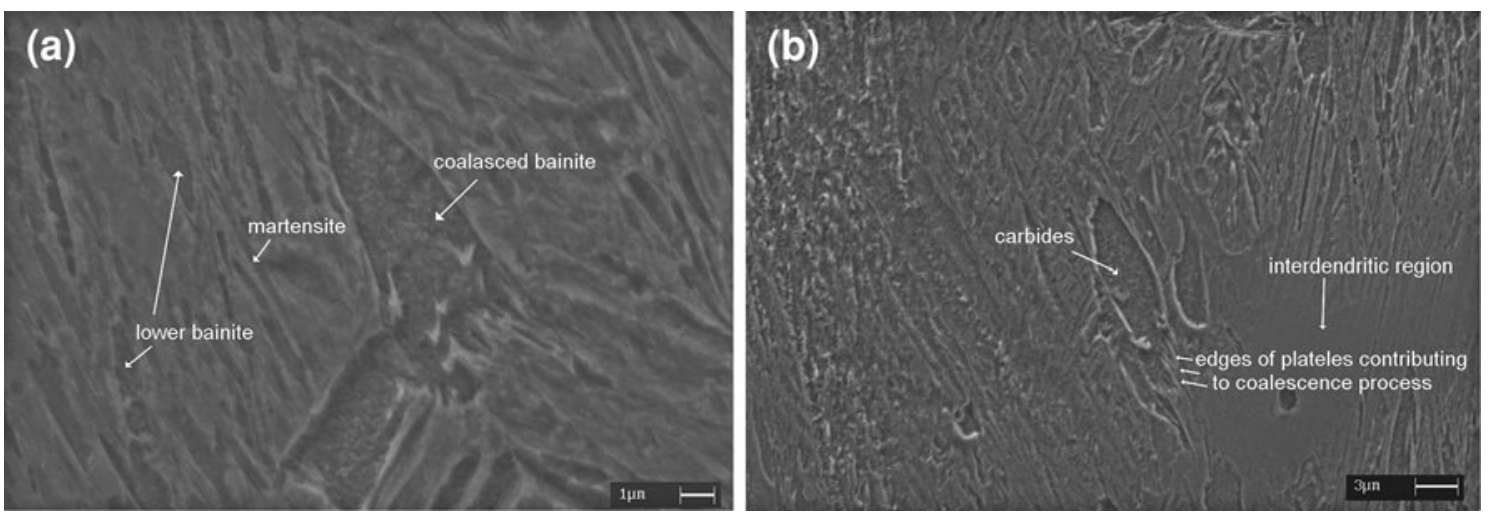

Fig. 8 SEM-SE image of a sample S5 and b sample S6 (etched with nital)

because of their similar morphologies at these magnifications (Fig. 4a-c). Increasing the cooling rate led to a finer microstructure, as shown in Fig. 4(d). Moreover, in all samples, it is possible to distinguish the former dendrite boundaries that are represented by the lighter zone in the image, e.g., the area not attacked after etching with nital (Fig. 5).

The amount of bainite was determined through image analysis of the samples, after an etching treatment that reveals bainite in the steel as the darkest microstructural constituent (Fig. 5a-d). The bainite amount increased with the cooling rate until the value of $0.1{ }^{\circ} \mathrm{C} / \mathrm{s}$ and then decreased as martensite began to form, in agreement with the results of DSC (Table 4). However, the values derived from the image analysis are to be considered approximate, since the zones corresponding to the former dendrite zone were not etched.
Figure 6 shows the SEM-SE images of the samples cooled at the different rates. Depending on the cooling rate, the following phases were detected in the steel: upper bainite, lower bainite, martensite and retained austenite.

Bainite is a nonequilibrium product of austenite which evolves when cooling is at rates such that diffusion-controlled transformation such as pearlite is not possible and yet, the cooling is sufficiently slow to avoid diffusionless transformation into athermal martensite. Bainite microstructures are generally described as nonlamellar aggregate of plate-shaped ferrite and carbides. Bainite can be classified according to its morphology as upper bainite, forming at higher temperatures; and lower bainite, forming at lower temperatures. Both upper and lower bainites tend to form as aggregates of small platelets or laths (subunits) of ferrite. The essential difference between upper and lower 
bainites is in respect of the carbide precipitates. Upper bainite consists of clusters of ferrite platelets adjacent to each other, in almost crystallographic orientation, with elongated carbides particles that usually surround the boundaries of ferrite platelets. At higher temperatures, the carbon escaping is enough, while as the transformation temperature is reduced, some of the carbon precipitates within the ferrite plates as carbides, leading to the lower bainite formation. The fact that bainite growth is diffusionless leads to regions of austenite remaining untransformed [19].

In the samples cooled at the lower rates, it is possible to recognize the presence of upper bainite with the typical needle-type structure and with retained austenite between the needles (Figs. 6a, b, 7a). The needles are $3-20 \mu \mathrm{m}$ in length and $0.5-3 \mu \mathrm{m}$ in width.

In the samples cooled at rates higher than $0.15{ }^{\circ} \mathrm{C} / \mathrm{s}$, a mixture of martensite and lower bainite was detected, along with an uncommon coarse-grained variant of bainite (Fig. 6c-f). For the samples cooled at higher rates, only lower bainite was present (Fig. 7b). As mentioned above, the lower bainite forms at a higher cooling rate, and it differs from the upper bainite in the microstructural characteristics of the carbides. In the lower bainite, carbides grow mostly inside the ferrite plates at a characteristic angle with respect to the ferrite plate and with characteristic habit planes.

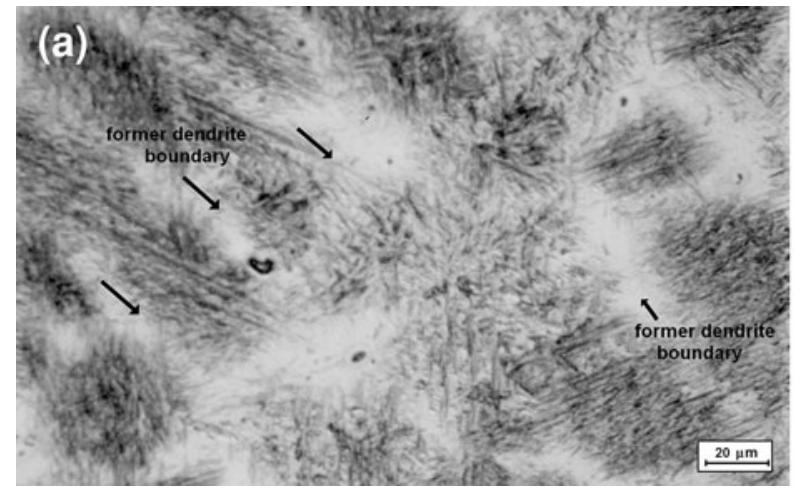

The coarse-grained phase detected in the samples subjected to the higher cooling rate was identified as coalesced bainite (Fig. 8a). Coalesced bainite is believed to form through coalescence of individually nucleated bainitic ferrite platelets with identical crystallographic orientation. Two conditions have been proposed to be necessary for the occurrence of coalesced bainite: (i) there must be an adequate driving force (chemical free energy change) to sustain the greater strain energy associated with the coarser plate and, (ii) the lengthening of subunits must be allowed to proceed without hindrance $[20,21]$. The mobility of carbon plays a role in making coalescence achievable and a delay of the partitioning of carbon into the residual austenite should make it easier for plates to coalesce. In Fig. 8(b), the typical microstructure of coalesced bainite is shown, where the plate contains carbide particles and the edges of platelets contributing to coalescence process are visible.

From the results of SEM analysis, it is possible to conclude that for cooling rates up to the value of $0.1{ }^{\circ} \mathrm{C} / \mathrm{s}$ (sample S3), the microstructure contains mainly bainite and retained austenite, while for cooling rates higher than $0.1{ }^{\circ} \mathrm{C} / \mathrm{s}$, the martensite phase was also detected. This confirms the assumption made above, for which the first exothermic peak in DSC thermograms was attributed to austenite $\rightarrow$ bainite transformation and the second peak to the austenite $\rightarrow$ martensite transformation. Indeed, in DSC

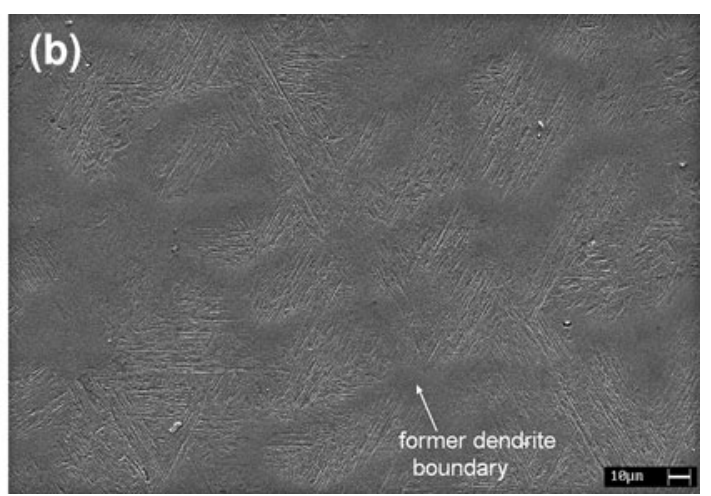

Fig. 9 Image of sample S6: a LM image and b SEM-SE image (etched with nital)
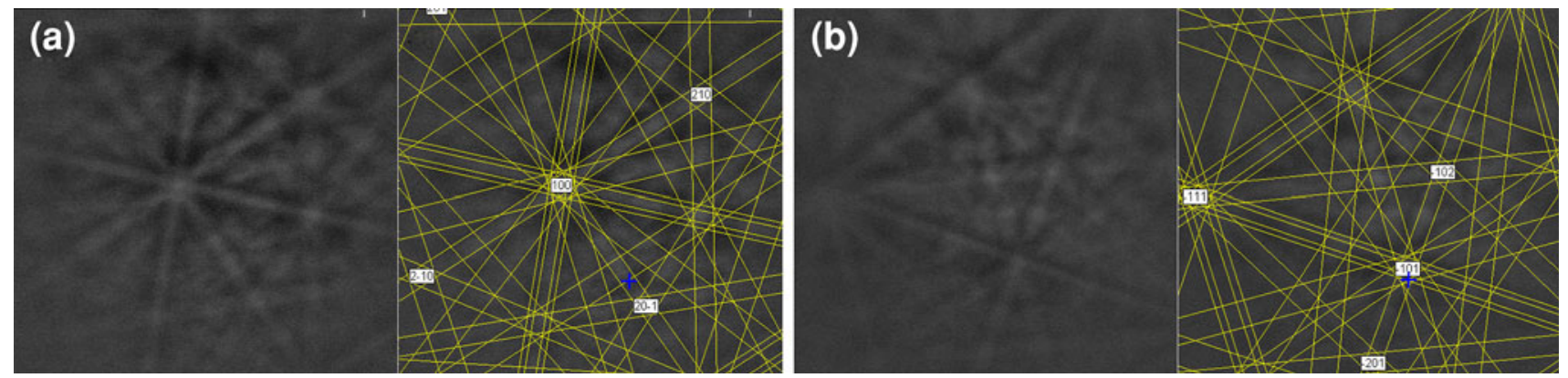

Fig. 10 Representative examples of two EBSD patterns indexed as $\alpha$-ferrite or martensite: a, b (left) raw patterns; a, b (right) indexed patterns 

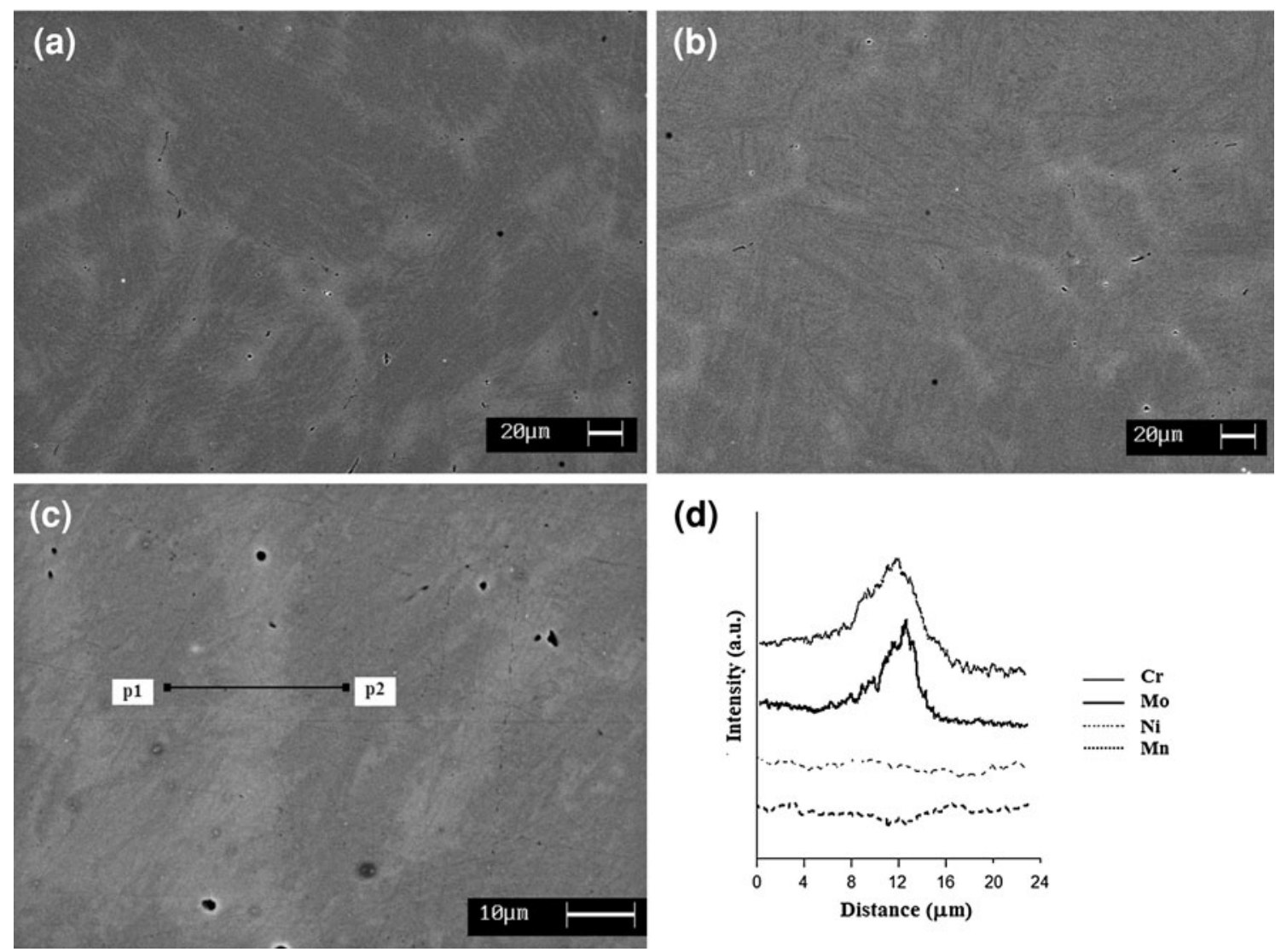

Fig. 11 SEM-BSE image of a sample S1; b sample S4; $\mathbf{c}$ higher magnification of sample S4; and $\mathbf{d}$ EDS elemental profiles between p1 and p2

thermograms, it is possible to see the peak attributed to austenite $\rightarrow$ martensite transformation only in the sample cooled at $0.15{ }^{\circ} \mathrm{C} / \mathrm{s}$ (sample S4) and for cooling rates higher than this value.

The SEM-SE images, as well as LM images, highlighted, in all the samples, the presence of the former dendrite boundaries, in correspondence of the zones where etching was not effective (Fig. 9a, b). EBSD analysis was performed in these zones and 15 points, manually acquired, were registered when sharp patterns were produced. The pattern indexing excluded the presence of austenite: all patterns were always indexed as the phase $\alpha$-ferrite or martensite (the lattice parameters of these two phases are too similar to provide a certain discrimination between them, under these analytic conditions) (Fig. 10a, b).

When as-polished samples were examined with SEM in the backscattered electron (BSE) mode, in all samples, a clear contrast between dendritic core regions and interdendritic regions was observed (Fig. 11a-c), suggesting that elemental segregation across the former dendrites occurred. EDS profile analysis was performed across two dendritic core regions. Figure 11(d) shows the $\mathrm{Cr}$, Mo, Mn, and $\mathrm{Ni}$ elemental profiles of sample S4, where an enrichment of $\mathrm{Cr}$ and Mo elements in the interdendritic region, in
Table 5 Vickers hardness values of the samples

\begin{tabular}{lllllllll}
\hline Sample & As cast & S1 & S2 & S3 & S4 & S5 & S6 & S7 \\
\hline $\mathrm{HV}_{0.2}$ & 410 & 500 & 540 & 590 & 640 & 645 & 650 & 700 \\
\hline
\end{tabular}

comparison with the dendrite core, is evident; $\mathrm{Mn}$ and $\mathrm{Ni}$ profiles do not exhibit discontinuities between the two different regions. Elemental segregation is a common phenomenon in the cast steel, and its main cause is solute rejection during freezing, due to the lower solubility of solute elements in the solid as compared with the liquid. The dendrite core is the first solid to form, and $\mathrm{Cr}$ and $\mathrm{Mo}$ are rejected from the solid into the liquid during solidification. From thermodynamic simulation, it was found that this steel solidified completely as austenite, and this may explain the segregation observed in the interdendritic region. When solidification has taken place, diffusion of substitutional elements is much more limited in the austenite lattice than in the ferrite lattice [22].

The segregation of $\mathrm{Cr}$ and Mo to the interdendritic regions results in depletion of these elements in the dendritic core regions, and this segregation can have a strong effect on the development of the microstructures. $\mathrm{Cr}$ and Mo influence the phase transformation, since they are 
Fig. 12 CCT diagram developed from the data collected in this study. UB and LB correspond to upper bainite and lower bainite, respectively

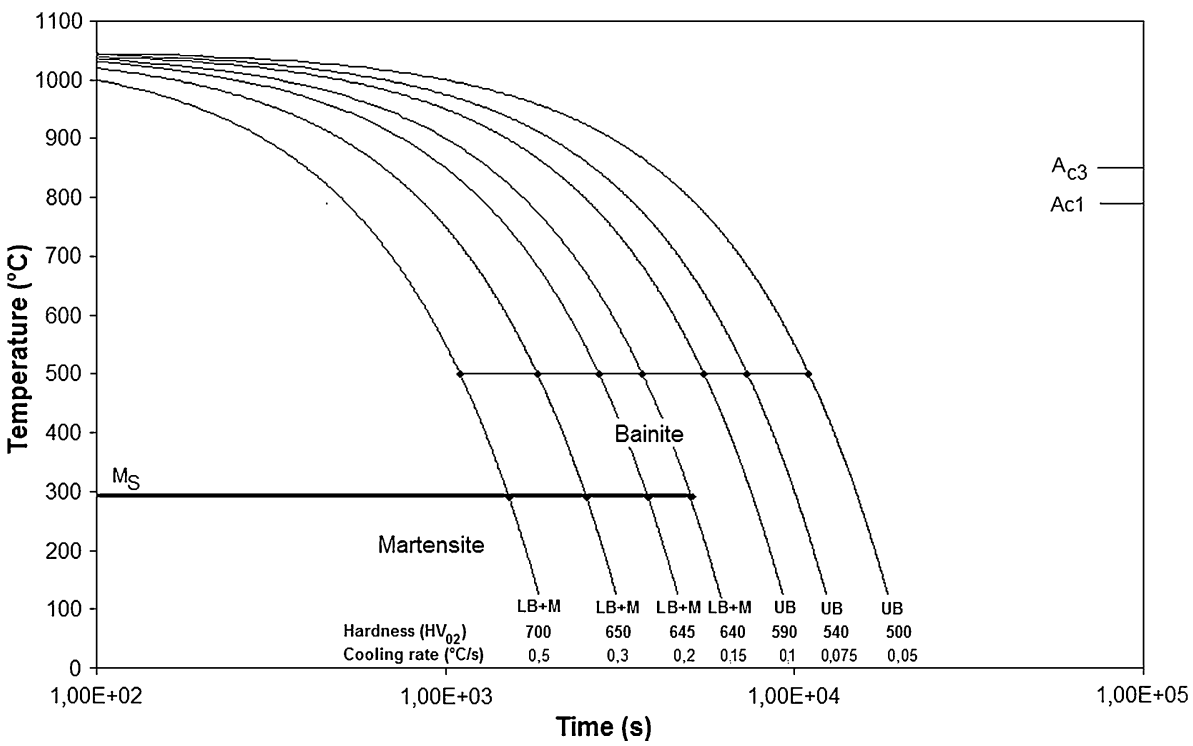

ferrite-stabilizing and carbide-forming elements. Their effects on decreasing the $M_{\mathrm{S}}$ temperature are well known, while their influence on $B_{\mathrm{S}}$ temperature is not so easy to predict. In fact, according to the thermodynamic theory of Bhadeshia for bainitic transformation, an increase in $\mathrm{Cr}$ reduces $B_{\mathrm{S}}$ temperature, and an increase in Mo increases $B_{\mathrm{S}}$ temperature. The neural network model proposed by Garcia-Mateo predicts (i) a linear trend of reducing the $B_{\mathrm{S}}$ temperature with increasing $\mathrm{Mo}$, and (ii) a nonlinear behavior for $\mathrm{Cr}$, with a reduction in $\mathrm{Cr}$ influence in decreasing $B_{\mathrm{S}}$ above concentrations of $4 \mathrm{wt} \%$ [23]. In this study, a variation in the concentrations of $\mathrm{Mo}$ and $\mathrm{Cr}$ was observed across the boundary between the dendrite core and the interdendritic region; $B_{\mathrm{S}}$ and $M_{\mathrm{S}}$ temperatures in the interdendritic region can therefore be expected to differ from those in dendritic core region.

The elemental segregation also explains the different behaviors of the interdendritic region when submitted to etching. The lack of etching response in the interdendritic region can be due to the higher amount of $\mathrm{Cr}$ and $\mathrm{Mo}$, which confers to this region a higher corrosion resistance. Moreover, the segregation of $\mathrm{Cr}$ and $\mathrm{Mo}$ in this steel could cause a local decrease in the difference between $M_{\mathrm{S}}$ and $B_{\mathrm{S}}$ at the interface between the interdendritc region and the dendritic core, thus promoting the formation of coalesced bainite [22], which was observed at interdendritic region/ dendritic core interface. The edges of platelets contributing to the coalescence process originated from the interdendritic region and were directed toward the dendritic core region (Fig. 8b).

The results of microhardness tests are summarized in Table 5. The as-cast sample showed a microhardness value of $410 \mathrm{HV}_{0.2}$ that is in agreement with those found for an upper bainite structure. Upon increasing the cooling rate from 0.05 to $0.1{ }^{\circ} \mathrm{C} / \mathrm{s}$, the upper-lower bainite structure became finer, and the measured hardness values increased $\left(590 \mathrm{HV}_{0.2}\right.$ for sample S3). At the cooling rate of $0.15{ }^{\circ} \mathrm{C} / \mathrm{s}$, martensite began to form, and the hardness value was $640 \mathrm{HV}_{0.2}$. At higher cooling rates, the amount of martensite increased, and consequently the hardness value also increased. The highest value $\left(700 \mathrm{HV}_{0.2}\right.$ ) was recorded for the sample cooled at the rate of $0.5^{\circ} \mathrm{C} / \mathrm{s}$ and was correlated to the higher amount of martensite. Moreover, in the sample treated with a cooling rate higher than $0.15{ }^{\circ} \mathrm{C} / \mathrm{s}$, coalesced bainite was observed. As reported in the study of Caballero et al. [24], the coalesced bainite, in addition to the depletion of the toughness of the steel, produces an increase in hardness. In these samples, it is difficult to distinguish the contribution of both martensite and coalesced bainite to the increase in hardness.

Based on analysis and interpretation of the data collected in this study, a CCT diagram for this steel was produced, where the temperatures of transformation, the microstructure, and the hardness are shown as a function of the cooling rate (Fig. 12).

\section{Conclusions}

A characterization of an air-hardening steel for rock-crushing industry was performed, using DSC and microstructural investigations. From the DSC thermogram, obtained during continuous heating, the temperature of magnetic transformation $(T \mathrm{c})$, austenite onset temperature $\left(A_{\mathrm{C} 1}\right)$, and austenite finish temperature $\left(A_{\mathrm{C} 3}\right)$ were determined. The exothermic peaks present in the DSC thermogram, obtained during continuous cooling, were attributed to the bainite and martensite transformations, and the corresponding $B_{\mathrm{S}}$ and $M_{\mathrm{S}}$ were determined. The experimental data of the 
transformation temperatures were compared with the temperatures obtained by a number of well-known empirical equations, based on the chemical composition of the steels. The model developed by Kunitake and Okada was more in agreement for the prediction of $B_{\mathrm{S}}$ than the other models.

Microstructural investigation showed that in all samples after the DSC thermal cycle, it was possible to distinguish the bainite phase. In the samples that were cooled at rates higher than $0.15^{\circ} \mathrm{C} / \mathrm{s}$, martensite phase was also detected. Moreover, both $\mathrm{Cr}$ and Mo segregations into interdendritic regions was observed.

Comparing the data from the various techniques, it can be stated that the first peak observed during cooling, starting at about $500{ }^{\circ} \mathrm{C}$, corresponds to the austenite $\rightarrow$ bainite transformation, while the second peak at about $290{ }^{\circ} \mathrm{C}$ corresponds to the austenite $\rightarrow$ martensite transformation. Hardness measurements are in good agreement with the observed microstructures.

\section{References}

1. G.J. Cox, Development of IN-646, a cast wear-resistant, air hardening steel. Foundry Trade J. 13, 633-638 (1975)

2. G.P. Krielaart, C.M. Brakman, S. Van Der Swaag, Analysis of phase transformation in $\mathrm{Fe}-\mathrm{C}$ alloys using differential scanning calorimetry. J. Mater. Sci. 31, 1501-1508 (1996)

3. M. Gojic, L. Kosec, P. Matrovic, The effect of tempering temperature on mechanical properties and microstructure of low alloy $\mathrm{Cr}$ and CrMo steel. J. Mater. Sci. 33, 395-403 (1998)

4. M. Gojic, M. Suceska, M. Rajic, Thermal analysis of low alloy Cr-Mo steel. J. Therm. Anal. Calorim. 75, 947-956 (2004)

5. W.F. Hemminger, H.K. Cammenga, Methoden der Thermishen Analyse (Springer, Berlin, 1989)

6. R.F. Speyer, Thermal Analysis of Materials (Marcel Dekker, New York, 1994)

7. S. Raju, B. Jeya Ganesh, A. Banerjee, E. Mohandas, Characterisation of thermal stability and phase transformation energetics in tempered 9Cr-1Mo steel using drop and differential scanning calorimetry. Mater. Sci. Eng. A 464, 29-37 (2007). doi: 10.1016/j.msea.2007.01.127

8. C. Garcia De Andres, F.G. Caballero, C. Capdevilla, L.F. Alvarez, Application of dilatometric analysis to the study of solid-solid phase transformations in steels. Mater. Charact. 48, 101-111 (2002)

9. R.L. Bodnar, T. Ohhashi, R.I. Jaffe, Effects of Mn, Si and purity on the design of $3.5 \mathrm{NiCrMoV}, 1 \mathrm{CrMoV}$, and $2.25 \mathrm{Cr}-1 \mathrm{M} 0$ bainitic alloy steel. Metall. Trans. A 20A, 1445-1460 (1989)

10. H.K.D.H. Bhadeshia, Bainite in Steel (The Institute of Materials, London, 1992)

11. J.M. Robertson, The microstructure of rapidly cooled steel. J. Iron Steel Inst. 119, 391-419 (1929)

12. E.S. Davenport, E.C. Bain, Transformation of austenite at subcritical temperatures constant. Trans. Met. Soc. AIME 90, 117-154 (1930)

13. W. Steven, A.G. Haynes, The temperature of formation of martensite and bainite in low alloy steels. J. Iron Steel Inst. 183, 349-359 (1956)

14. J.S. Kirkaldy, D. Venugopalan, In: Phase Transformations in Ferrous Industry, A.R Marder, J.I. Goldstein (eds.), TMS-AIME, Warrendale, PA, pp 125 (1984)

15. Z. Zhao, C. Liu, Y. Liu, D.O. Northwood, A new empirical formula for the bainite upper temperature limit of steel. J. Mater. Sci. 36, 5045-5056 (2001)

16. H.E. Boyer, Atlas of Isothermal transformation and Cooling Transformation Diagrams, American Society for Metals, Metals Park, pp 52 (1977)

17. T. Kunitake, Y. Okada, The estimation of bainite transformation temperatures in steels by the empirical formulas. J. Iron Steel Inst. 84, 137-141 (1998)

18. K.W. Andrews, Empirical formulae for the calculation of some transformation temperatures. J. Iron Steel Inst. 203, 721-727 (1965)

19. H.K.D.H. Bhadeshia, A.R. Waugh, Bainite: an atom probe study of the incomplete reaction phenomenon. Acta Metall. 30, 775-784 (1982)

20. L.C. Chang, H.K.D.H. Bhadeshia, Microstructure of lower bainite formed at large undercoolings below the bainite start temperature. Mater. Sci. Technol. 12, 233-236 (1996)

21. H.K.D.H. Bhadeshia, E. Keehan, L. Karlsson, H.O. Andrén, Coalesced bainite. Trans. Ind. Inst. Met. 59, 689-694 (2006)

22. E. Keehan, L. Karlsson, H.O. Andrèn, H.K.D.H. Bhadeshia, New developments with $\mathrm{C}-\mathrm{Mn}-\mathrm{Ni}$ high strength steel weld metals, part A-microstructure. Weld. J. 85, 200s-210s (2006)

23. C. Garcia-Mateo, T. Sourmail, F.G. Caballero, C. Capdevila, C. Garcia de Andreis, New approach for the bainite start temperature calculation in steels. Mater. Sci. Technol. 21, 934-938 (2005)

24. F.G. Caballero, J. Chao, J. Cornide, C. García-Mateo, M.J. Santofimia, C. Capdevila, Toughness of advanced high strength bainitic steels. Mater. Sci. Forum 638-642, 118-123 (2010) 